Годишњак Филозофског факултета у Новом Саду, Кюига ХХХІХ-1 (2014)

Annual Review of the Faculty of Philosophy, Novi Sad, Volume XXXIX-1 (2014)

Dubravka Valić Nedeljković

UDK 342.849.2-055.2:316.774(497.11)"2012"

Filozofski fakultet Univerziteta u Novom Sadu 342.849.2-055.2 :316.774(497.11)"2014”

Originalan naučni rad

\title{
IZOSTANAK POLITIČARKI U PLAĆENOM OGLAŠAVANJU* PREDIZBORNI TV SPOT, SRBIJA 2012. I 2014
}

Cilj rada je da dekonstruiše strategije političkih partija iz rodne perspective u odnosu na televizijsko predizborno političko plaćeno oglašavanje u kampanjama 2012. i 2014. u Srbiji. Cilj je takođe da se analizira lično iskustvo političarki da bi se na nov i drugačiji način analizirale prakse i strategije partija u odnosu na vidljivost kandidatkinja u vreme predizborne kampanje u medijima. Metode korišćene $u$ istraživanju su: kritička analiza medijskog diskursa (jedinica analize je tv spot u celini, verbalna, vizuelna i zvučna komponenta), komparativna metoda i životne priče kandidatkinja. Osnovna hipoteza je da bez obzira na to što su, shodno zakonskim odredbama, na kandidatskim listama, u oba analizirana izborna ciklusa, žene zauzimale svako treće mesto - one su podzastupljene u plaćenom političkom medijskom reklamiranju (TV spotu). Osnovni rezultat je da su medijske plaćene kampanje bile maskulinizirane. U fokusu je samo partijski lider. Kandidatkinje su podzastupljene u oba posmatrana perioda. Partije nisu rodno senzibilisane kada je reč o političkom plaćenom oglašavanju u vreme predizborne kampanje.

Ključne reči: TV spot, izbori, kandidatkinje, podzastupljenost

\section{UVODNA RAZMATRANJA}

U samom središtu kritičke analize diskursa (CDA) nalazi se detaljno proučavanje koncepta moći. Poseban naglasak se stavlja na različite oblike diskriminacije koji nastaju kao rezultati zloupotrebe moći koji dalje vode ka pojavi društvenih nejednakosti i nepravde (Dijk 2008). Kritička analiza diskursa se bavi proučavanjem društvenih problema, nejednakosti, dominacije i sličnih fenomena, kao i ulogama koju diskurs, upotreba jezika ili komunikacija imaju u tim situacijama. U ovoj studiji ćemo samo delimično odgovoriti na ovaj metodološki izazov.

Pod diskursom se u CDA podrazumevaju: a) različiti tipovi društvene prakse. U ovom istraživanju to je predizborna kampanja za parlament i predsednika Srbije 2012 i parlamentarni vanredni izbori 2014. b) Vidovi komunikacije u nekoj

\footnotetext{
* Dubravka Valić Nedeljković, dnvlic@gmail.com. Rad je nastao u okviru obeležavanja 60 godina Filozofskog fakulteta i kao rezultat istraživanja u okviru Republičkog projekta Digitalne medijske tehnologije $i$ društveno-obrazovne promene Filozofskog Fakulteta u Novom Sadu koji Odsek za medijske studije realizuje od 2010. do 2014. Projekat finansira Republičko ministarstvo prosvete i nauke, šifra projekta III 47020.
} 
društvenoj, kulturnoj, istorijskoj ili političkoj situaciji. U ovom istraživanju to je plaćeno medijsko oglašavanje partija u predizbornoj kampanji 2012. I 2014. u kontekstu rodne ravnopravnosti i iz perspektive životnih priča kandidatkinja (oral history).

Ovaj rad je izvod iz jednog opširnijeg, longitudinalnog, istrazivanja o prisutosti žena u politici.

Valja imati na umu da politički TV spot predstavlja suštinu predizborne kampanje svake partije, dostupan je na celoj teritoriji zemlje, jednostavan je za razumevanje, motivišući je za birače i stoga partije izdvajaju znatna sredstava za ovaj oblik plaćenog predizbornog oglašavanja.

CDA u dekonstrukciji medijske prakse u velikoj meri uključuje kontekstualne informacije u kojima se kreira i percepira poruka.

\section{DRUŠTVENO-POLITIČKI I KULTURNI KONTEKST}

Postoje tri nivoa na kojima se uočava (ne)vidljivost žena u političkim procesima: a) u predizbornim kampanjama (ne)prisustvo žena na kandidačkim listama, a nakon izbora i u parlamentu; b) (ne)vidljivost žena u plaćenoj medijskoj kampanji i c) (ne)vidljivost žena u jeziku.

Praksa: a) Na osnovu „principa afirmativne akcije” žene postaju prisutnije na kandidatskim listama i u parlamentu uvođenjem kvota kao rezultat rodno senzibilisanog zakonodavstva (sve zemlje SEE - Jugoistočna Evropa/Zapadni Balkan). b) Žene su i dalje retko vidljive u predizbornom TV spotu kao najučinkovitijem plaćenom oglašavanju, jer je to tradicionalno muški ,prostor”, dok su žene aktivnije na terenu. c) Vidljivost žena u jeziku postiže se, na primer, primenom kodeksa rodno senzitivnog jezika (S. Savić 2004).

U ovom radu fokus je na tačkama (a) i (b), s tim da se (c) razmatra ograničeno, samo u okviru analize slogana predizbornog TV spota.

Podzastupljenost žena u političkoj sferi Srbije uprkos zadovoljavajućih zakonskih rešenja rezultat je neodgovarajuće primene zakona, kao i preovlađujućeg modela liderskih partija u kojima su muškarci uvek na čelu stranke.

Izborno zakonodavstvo Srbije jeste rodno senzibilno. Zakonodavac se odlučio 2003. da primeni u Zakonu o izboru narodnih poslanika meru afirmativne akcije koja podrazumeva uvođenje izbornih kvota ${ }^{1}$. Naime pokazalo se u praksi tokom ranijih kampanja u višepartijskom sistemu Srbije, koji nema dugu tradiciju, da su žene bile potisnute od strane muškaraca koji su dominirali političkom scenom. „Kvote predstavljaju samo prelaznu fazu ka paritetnoj demokratiji, način da se razbije politička inercija muške većine i način afirmacije i priznavanja ženskih sposobnosti“" (Mršević 2007, 37 f.). Činjenica da je svaka treća osoba na kandidacionim listama morala biti žena u izbornim ciklusima 2004. i 2008. nije nužno i

Zakon o izborun narodnih poslanika (2003) Poglavlje VI IZBORNA LISTA, 1. Kandidovanje, član 40a: „Na izbornoj listi među svaka tri kandidata po redosledu na listi (prva tri mesta, druga tri mesta i tako do kraja liste) mora biti najmanje po jedan kandidat - pripadnik onog pola koji je manje zastupljen na listi”. 
značilo da su tako bila raspoređena i mesta u parlamentu, naprotiv. Stoga je za kampanju 2012. usvojen amandman (2011) Zakona o izboru narodnih poslanika da svako treće mesto pripada ženi u parlamentu. Efikasnost sistema kvota vidljiva je kada se uporedi broj žena poslanica u parlamentu Srbije nakon prvih višestranačkih izbora održanih 9.decembra 1990. (1,6\% žena), i nakon izbora 6. maja 2012. (32,8\% žena) i 6. marta 2014. (34\%). Sve kandidatkinje iz Srbije intervjuisane za potrebe ovog istraživanja su podržale sistem kvota.

„Nikad se nije desilo da je žena više u parlamentu bez kvote nego sa kvotom. To je ujedno onda i šansa da budu vidljivije i u javnosti“ (Maja Sedlarević, Liga socijaldemokrata Vojvodine).

„Ja sam u dubini duše protiv uvođenja kvota, jer su nam zapravo potrebne jake, kvalitetne, obrazovane, sposobne žene, a ne neko ko je samo ženskog pola, a inače ćuti i smeška se. Međutim, vrlo sam svesna i da su kvote trenutno i još uvek neophodno zlo za primoravanje muškog sveta da i nas uključe u politički život“ (Elvira Kovač, Savez Vojvođanskih Mađara).

Ovom afirmativnom akcijom Srbija je implementirala i jedan od značajnih Milenijumskih ciljeva ${ }^{2}$ Ujedinjenih nacija kojim se, kao i CEDAW Convention (usvojena u Ujedinjenim nacijama 1979. ) zagovara ravnopravno učestvovanje žena sa muškarcima u donošenju odluka u političkom životu.

Izborne kvote omogućuju predviđenu brojčanu zastupljenost žena na kandidatskim listama i u parlamentu nakon izbora, ali ne i njihovu stvarnu vidljivost, osim istaknutih pojedinki, kako unutar stranke, tako i u vreme predizborne kampanje (na terenu i u medijima) i na kraju u aktivnostima u samom parlamentu. „Nasleđene kulturološke predrasude i stereotipi tradicionalističkog truštva u kojem je poziv političara maskuliniziran, u kojem se žene odgajaju tako da nemaju ambiciju da budu donosioci odluka i da zauzimaju liderske pozicije, a stranke u svojim programima rodnu ravnopravnost navode samo deklarativno" (Mršević 2007), otežavaju političarkama pozicioniranje u javnoj sferi koja je obremenjena autoritarnom političkom kulturom u kojoj je uvek nametnut ideal vođe muškarca.

„Kvotom kao skalpelom isečeš okvir za političku reprezentativnost i onda time menjaš prirodu moći. To je cilj kvota, a ne samo naš broj” (Gordana Čomić, Demokratska stranka).

„Žene iz različitih partija su se ujedinile, na trenutak su pribegle muškom principu lobirale su za kvote i čak su tada odustale od partijske discipline i glasale su za svoju žensku reprezentativnost u parlamentu i uspele" (Vesna Šijački, direktorka Zavoda za ravnopravnost polova Vojvodine).

Manje su uspešne kada treba da se izbore da zajedno sa svojim partijskim kolegama učestvuju na predizbornim treninzima čiji je cilj afirmacija rodne ravnopravnosti i u društvu i u kampanji.

„Predsednici opštinskih odbora partija, šefovi izbornih štabova sve sami muškarci uopšte nisu otvoreni za treninge, a partijske koleginice osujećuju tako što im ne

2 The United Nations Millennium Development Goals are eight goals that all 191 UN member states have agreed to try to achieve by the year 2015. Goal 3 Promote Gender Equality and Empower Women; Indicators 12: Proportion of seats held by women in national parliament (IPU) http://www.unmillenniumproject.org/ goals/gti.htm\#goal3 
omogućavaju tehničku podršku da odu na edukaciju, ali ipak su se žene osnažile i bore se da dođu.“(Vesna Šijački)

Mediji danas imaju odlučujuću ulogu u predizbornim kampanjama. „Najveći broj građana osnovne informacije o izbornim učesnicima dobija preko medija i nema nikakvog direktnog kontakta ni sa kandidatima ni sa njihovim izbornim platformama" (Matić 2002, 11 f.). Stoga se u svim pomenutim izbornim zakonima insistira na ravnopravnom tretiranju svih učesnika u medijima tokom predizborne kampanje, ali ne sa rodnog stanovišta. Praksa međutim pokazuje da su u Srbiji kandidatkinje podzastupljene u medijima u odnosu na lidere partija i njihove partijske kolege, kandidate, u predizbornim kampanjama (Matić 2002; Slavujević 2007; Valić Nedeljković 2008).

\section{IZBORI 2012. I 2014. U SRBIJI}

Izbori su bili opšti (lokalni, pokrajinski, parlamentarni i za predsednika Republike).

Izborna trka 2012. vodila se između koalicije koju je predvodila Demokratska stranka koja je u protekla dva mandata formirala vladu (centar) i Srpske napredne stranka (populistička partija desnog centra koja je bila u opoziciji. Ostale partije su bile u njihovoj senci.

Za 250 mesta u Skupštini Srbije za izbore se kandidovalo 18 lista sa 3065 osoba. Na listama je bilo 32\% kandidatkinja i 68\% kandidata. Liste su postavljale partije i koalicije.

Za mesto predsednika Republike kandidovalo se 8 muškaraca i 2 žene. Kandidatkinja desničarske Srpske radikalne stranke osvojila je 3,7\% glasova (sedmo mesto), a kandidatkinja Socijaldemokratskog saveza sa 0,78 odsto glasova je na poslednjem mestu.

U sazivu 2012. Skupštine Srbije 32,8\% su žene, vlada je koaliciona desnog centra okupljena oko SNS i levice okupljene oko Socijalističke partije Srbije (SPS, bivša Miloševićeva partija).

Izbori su protekli u atmosferi velike ekonomske i finansijske krize, recesije i rekordne stope nezaposlenih $(25,5 \%)^{3}$ među kojima prednjače žene $(26,1 \%)$.

U medijskoj prezentaciji programi svih izbornih lista u Srbiji 2012. su bili isti: poboljšanje ekonomske situacije i otvaranje novih radnih mesta, bez fokusiranja na zapošljavanje žena.

Na vanrednim parlamentarnim izborima bilo je 19 lista čiji nosioci su bili partijski lideri sve muškarci. Na listama je bilo ukupno 3.020 kandidata i kandidatkinja za 250 poslaničkih mesta. Od navedenog broja 1.087 ili 36 odsto činile su žene.

Najaktivnija stranka u predizbornoj kampanji bila je do tada vladajuća SNS koja je 2014. osvojila je čak 48,44 odsto glasova i ima 158 mandata. „Polje sukoba” $\mathrm{u}$

http://www.euractiv.rs/srbija-i-eu/4339-stopa-nezaposlenosti-u-srbiji-rekordnih-255

4 Termin preuzimamo iz teorija debatovanja. Podrazumeva temu koja nakon vođenja javne diskusije ostaje, od celog ponuđenog spektra, najupečatljivija. 
predizbornoj kampanji 2014. takoreći nije ni postojalo, sve stranke su se zalagale za ekonomski boljitak, pošto se situacija na tržištu rada pogoršala, a privredna stabilizacija, obećavana u kampanji 2012, izostala. Međutim, cilj kampanje, u ovom slučaju, se može smatrati ,poljem sukoba”. Jer, sa stanovišta SNS cilj je bilo osvajanje potpune vlasti, a sa stanovišta DS i Nove demokratske stranke (NDS), opstanka na političkoj sceni Srbije.

U novom parlamentu Srbije sedi 85 žene (34\%) i 165 muškaraca (66\%).

\section{KOMUNIKATIVNE STRATEGIJE U RODNOM KLJUČU}

Komunikativnim strategijama predstavljanja žena u medijima koje su direktno, ili indirektno, vezani za političarke u/i oko predizborne kampanje, bavili su se mnogi istraživači, na posredan, ili neposredan, način, uglavnom u interdisciplinarnim istraživanjima i to iz različitih perspektiva. Jedna grupa istraživanja se bavila razmatranjem samog tipa kampanje koju kandidati vode, a mediji ih samo prenose (na primer u: Salmon, 2011; King, McConnell, \& Jason, 2003). Druga je fokus imala na to da ,otkriva kako jezik funkcioniše kao simbolički resusrs za kreiranje i upravljanje ličnim, društvenim i kulturnim značenjima i identitetima" (Kendall \&Tannen, 2010, 548 f.), u okviru kojih su i istraživanja o stereotipima i predrasudama posredovanim jezikom (Sanbonmatsu, \& Dolan, 2009; Moranjak-Bamburić, Jusić, Isanović, 2006) čiji rezultati su veoma upotrebljivi za analizu medijske prezentacije govora političara/političarki tokom kampanje. Istraživači su se posebno bavili u okviru predizbornih kampanja, seksizmom (Carolin \& Winfrey, 2009). Zatim su tu istraživanja koja se direktno tiču kandidatkinja/izbora/medija. Jedno od ređih iz ove grupe upravo se bavi temom koja nas neposredno interesuje o prezentaciji žena u tv spotovima. Montague i Paige (1994, 80 f.) govore o „potrebi žena da predstave svoj javni i privatni svet biračima”. Praćenje kampanje sa stanovišta prezentacije političarki u Bugarskim medijima i komparativno onima iz bivše Istočne Evrope bavili su se i Ibroscheva, i Raicheva-Stover, (2009, 441 f.) i zaključile da ,jednostavan obrazac rodnih razlik nije na površni." U okviru ove teme različiti su fokusi tako se na primer Zeldes i Fico, (2005, 373f.) usredsredjuju na način na koji su novinari i novinarke pratili predsedničke izbore i na to ko su im izvori i zaključuju da su ,priče koje su kreirale žene i izveštači koji pripadaju manjinama, koriste kao izvor informacija žene i manjine, koje nisu kandidati na izborima, dajući im dovoljno vremena, što nisu činili muškarci i belci izveštačì”. Analizirano je, iz komparativne perspective, postizborno pisanje o ženama na čelu države (Cantrell, \& Bachmann, 2008, 429 f.). Autori zaključuju da se ,prezentacija vesti normalizuje i postaje rutinizirana u odnosu na kulturni, socijalni i politički kontekst" kada se kampanja završi. Poseban tip istraživanja

\footnotetext{
Nastale cepanjem DS na dve partije: DS na čelu koje je aktuelni predsednik stranke Dragan Đlas i NDS koju sa istomišljenicima i sledbenicama koji su napustili, nakon izbornog poraza 2012, DS, formira do tada počasni predsednik DS Boris Tadić, ujedno i najveći gubitnik u izbornom ciklusu 2012. (izgubio reizbor za predsednika Srbije, smenjen sa mesta predsednika DS).
} 
čine ona o političarkama u različitim kontekstima, a skandali su oni koji ulaze u navažniji sadržaj medija (Kroon, \& Ekström, 2007) ujedno je to i prostor za stereotipizaciju prezentacije političarki u odnosu na političare u jednoj ekstremnoj situaciji. Ne manje zanimljiva su istraživanja iz rodne perspektive koja u fokusu imaju rodnu pripadnost potencijalnih birača, i njihov odnos prema medijskoj prezentaciji kampanje (Kaid \& Holtz-Bacha, 2000, 17f.).

U ovom radu se bavimo, komparativno, (ne)vidljivošću političarki u predizbornoj kmpanji kroz a) analizu diskursa predizbornog TV spota u kontekstu rodne zastupljenosti, kao i kroz b) životne priče političarki (oral history) o njihovom ličnom iskustvu prisutnosti žena u vreme predizborne kampanje u Srbiji.

\section{CILJ}

Cilj istraživanja je da se iz rodne perspektive dekonstruišu strategije partija u oblasti rodne senzibilisanosti i to u najvažnijoj aktivnosti parlamentarne demokratije - izbornom ciklusu na primeru političkog plaćenog oglašavanja - predizbornog TV spota na koji su stranke izdvojile najviše sredstava u kampanji 2012. i 2014. u Srbiji.

Cilj je takođe da se analizira lično iskustvo političarki da bi se na nov i drugačiji način analizirale prakse i strategije partija u odnosu na vidljivost kandidatkinja $u$ vreme predizborne kampanje medijima.

\section{METOD I KORPUS}

Za ostvarivanje istraživačkih ciljeva korišćene su tri metode.

a) Kritička analiza diskursa predizboprnog tv spota na osnovu kvantitativno-kvalitativne analize sadržaja sa akcentom na kvalitativnu analizu.

Jedinica analize je predizborni tv spot u celini (verbalna i vizuelna komponenta).

Analizirani predizborni TV spotovi snimani su na svim nacionalnim televizijama. Ukupan korpus iznosi 100 različita politička tv spota 11 političkih partija u kampanji 2012. za sva četiri nivoa izbora. Na srpskom jeziku 99, jedan na mađarskom jeziku. Najkraći spot je trajao 8 sekundi (ultra desni centar Demokratska stranka Srbije (DSS), je insistirala na kratkim spotovima). Najduži 78 sekundi (Demokratska stranka, je insistirala na dugim spotovima). Ovaj nalaz nije neobičan kada se ima u vidu da je DSS partija koja ima jako malo poslanika te su joj i prihodi skromni, a spot se naplaćuje po sekundama. DS je imala izuzetno puno poslanika i formirala vladu, znači imala je mnogo više sredstava za plaćeno oglašavanje. U kampanji 2014. situacija je bila potpuno drugačija. Plaćeno predizborno reklamiranje TV spotom je bilo dostupno samo za devet, od 19 lista. Različitih spotova je bilo znatno manje u medijskoj ponudi nego 2012. Tako da ih je analizirano ukupno 36 i to: „Dosta je bilo” (1 spot), Demokratska stranka Srbije/DSS (1 spot), „Dveri” (1 spot), Demokratska stranka/DS (2 različita spota), Ujedinjeni regioni Srbije/URS (4 različita spota), Nova demokratska stranka/NDS (6 razli- 
čitih spotova), Srpska napredna stranka/SNS (6 različitih spotova), Socijalistička partija Srbije/SPS (7 različitih spotova), Liberalno-demokratska partija/LDP (8 različitih spotova). Korpus čine emitovani predizborni TV spotovi od druge sedmice kampanje (februar 2014), pa do predizborne ćutnje (14. mart 2014). U analizu nije uključen broj emitovanja svakog pojedinačnog tv spota. Najkraći je trajao 8 sekundi, najduži minut.

b) Komparativan metoda anlize diskursa predizbornih TV spotova u kampanji 2012. sa kampanjom 2014.

c) Metod životne priče žena (Oral history) kandidatkinja na izborima 2012 koje su ušle u skupštinu na republičkom i pokrajinskom nivou. Pošto vanredni izbori 2014. nisu uključivali Pokrajinsku skupštinu, intervjuisane poslanice 2012. iz Pokrajinske skupštine su u važećem sazivu.

„Danas je u feminističkoj metodologiji jedan od važnih načina sakupljanja emprijskog materijala metod životne priča žena (oral history) u kojoj se podaci iz ličnog iskustva žena analiziraju uzimanjem u obzir društvenih, istorijskih i, pre svega, kulturnih elemenata konteksta u kojem žene žive, kako bi se na nov način interpretirali događaji iz bliže i dalje istorije koliko i iz perspektivne savremenosti" (Savić, 2012, $124 \mathrm{f}$ ).

Za beleženje životnih priča o predizbornoj kampanji korišćena je tehnika dubinskog intervjua sa unapred pripremljenih 15 pitanja istih za sve političarke. Intervjuisane su četiri političarke koje imaju bogato iskustvo kao kandidatkinje u kampanjama i uspešne parlamentarke na nacionalnom i pokrajinskom nivou ${ }^{6}$ različite starosti, obrazovanja, nacionalne i partijske pripadnosti.

Osim poslanica intervjuisani su još i direktorica Zavoda za ravnopravnost polova Vojvodine, Vesna Šijački (VŠ) koja je pred kampanju 2012. organizovala i učestvovala kao radioničarka na treninzima političarki i političara svih partija u 16 opština u Vojvodini. Kreativni direktor agencije IDEA+ Toni Laurenčić (TL IDEA+), do sada realizovao 30 kampanja u regionu Jugoistočne Evrope.

Svaki intervju je trajao 60 minuta. Ukupno je snimljeno i analizirano šest sati dubinskih intervjua.

\footnotetext{
Potpredsednica Skupštine Srbije u dva mandata Gordana Čomić (GČ), Demokratska stranka/DS (centar), vladajuća partija od 2000. do 2012, kada je izgubila šansu da formira vladu i izgubila mesto predsednika Republike. U prošlom mandatu potpredsednica Skupštine Vojvodine, u mandate 2012. predsednica Skupštinskog odbora za evropske integracije i međuregionalnu saradnju Skupštine Vojvodine Maja Sedlarević $(M S)$, poslanica Lige socijaldemokrata Vojvodine/LSV (najjača stranka levog centra koja se zalaže za punu autonomiju Vojvodine), parlamentarna stranka. Narodna poslanica, članica Odbora za ljudska i manjinska prava i ravnopravnost polova Skupštine Srbije, u dva mandata najmlađa poslanica u Skupštini Srbije Elvira Kovač (EK), Savez Vojvođanskih Mađara/SVM (demokratski centar, najsnažnija partija nacionalne mađarske manjine). Predsednica odbora za ravnopravnost polova Skupštine Vojvodine Stojanka Lekić (SL), Srpska napredna stranka (desni centar). Druga po snazi partija u Srbiji, do izbora 2012. uvek u opoziciji, glavni rival na svim izborima Demokratske stranke. Nakon izbora 2012. formirala vlade na svim nivoima i osvojila mesto predsednika republike; 2014. osvojila 44,48\% glasova i dobila 158 poslaničkih mandata. U vreme pisanja teksta pokreće inicijativu za vanredne izbore i na pokrajinskom nivou.
} 


\section{HIPOTEZE}

\section{Osnovna hipoteza}

H0: Bez obzira što su, shodno zakonskim odredbama, na kandidatskim listama u oba analizirana izborna ciklusa, žene kandidatkinje zauzimale svako treće mesto - one su podzastupljene u plaćenom političkom medijskom reklamiranju (TV spotu).

\section{Pojedinačne hipoteze}

H1: Žene u predizbornim TV spotovima zastupaju lik i delo lidera partije i nosioca liste.

H2: U vizuelnoj prezentaciji sadržaja spota kandidatkinje su podzastupljene

H3: Rodno senzitivan jezik nije prisutan u sloganu i telu spota

H4. Kandidatkinje nisu imale priliku da zastupaju svoje stavove i mišljenje u direktnim citatima u predizbornim tv spotovima.

\section{REZULTATI}

\section{OBIM PREDIZBORNOG PLAĆENOG OGLAŠAVANJA (TV SPOT)}

Predizbornim tv spotom se, može smatrati vid plaćenog političkog reklamiranja čiji je cilj da potencijalne birače u kratkoj kreativnoj audio-vizuelnoj formi informiše o najosnovnijim ciljevima i programu partije, odnosno kandidata. Važan je element kao „oruđe za obrazovanje i mobilisanje glasača, posebno u ruralnim oblastima [...] posebno u zemljama u razvoju gde žene, sa ograničenim sredstvima, mogu imati poteškoća da dopru do tih glasača" (Mršević 2007, 47 f.).

U predizbornoj kampanji 2012. od ukupnog plaćenog vremena 74,30 \% čine spotovi (RRA 2012) ${ }^{7}$. Ukupno je bilo na devet televizija sa nacionalnom frekvencijom 12727 emitovanja promotivnih TV spotova. Ukupno trajanje emitovanja u toku dva meseca je četiri dana 10 sati 33 minuta i 10 sekundi.

Prema „Izveštaju o nadzoru nad radom emitera tokom predizborne kampanje za republičke i lokalne izbore 29.01.2014 -13.03.2014" Republičke radiodifuzne agencije (RRA) Srbije: „U predizbornoj kampanji 2014. godine, emitovano je ukupno 2 dana 3 sata 21 minut predizbornog plaćenog vremena (1 dan i 20 sati predizbornih oglasnih poruka, odnosno $85,70 \%$ i 7 sati 21 minut predizbornih plaćenih termina, odnosno $14,3 \%$ ) ukupno trajanje predizbornih oglasnih poruka u kampanji 2014. manje je 2,42 puta u odnosu na kampanju 2012.” Ponuda raznovrsnih tv spotova 2014. je bila 2,77 puta manja nego 2012. (100:36).

RRA - Republička radiodifuzna agencija, nije objavila zvanične podatke o emitovanim spotovima u lokalnim medijima. 
Smanjen obim političkog plaćenog oglašavanja zbog nedostatka novca za kampanju, zbog kratkoće kampanje, kao i zbog vanrednog raspisivanja izbora za koje je bila spremna samo vladajuća stranka koja je odabrala njoj najpogodniji termin, doprineo je da u fokusu spotova za parlamentarne izbore budu isključivo nosioci izbornih lista, dakle lideri stranaka. Za lokalne izbore (gradonačelnik/gradonačelnica Beograda) u TV spotu se pojavljuju kandidati/kandidatkinje za ovo prestižno mesto u političkoj ponudi Srbije.

\section{STRUKTURA TV SPOTA}

TV spot čine: slogan i telo spota.

Slogan čini ikonički i jezički deo. Jezički mora biti jednostavan i lak za pamćenje da bi ostvario ubeđivačku ulogu. „Gledamo da on bude rodno neutralan $\mathrm{i}$ da ga i muškarci i žene prepoznaju kao relevantan” (TL IDEA+).

Ikonički ima zadatak da asocijativnim putem profunkcioniše u izbornom danu i motiviše birače da zaokruže određeni broj na listi.

Samo jedna stranka je imala ženu kao zaštitno lice kampanje. Reč je o anonimnoj, mladoj urbanoj, ženi budućnosti, pobedničke desničarske stranke SNS. „Taj ženski lik je učinio tu partiju evropejskom, bez obzira da li ona to jeste ili nije i birači su to prepoznali." (TL IDEA+).

Kampanja 2012. iako nije u fokusu imala Evropu kao cilj političkog delovanja, ipak na implicitnom nivou je to bila značajna poruka.

Uočeno je da u svim analiziranim spotovima jezički deo slogana izgovara muški glas. Montague, Kern/ Paige P., Edley su u analizi političkih spotova došli do istog podatka "The majority of the ads employed male voice-overs” (1994, $82 \mathrm{f}$.) i zaključuju da "male voices give credibility to the women candidates" (1994, 82 f.).

Od ukupno 36 različitih slogana, u okviru 100 analiziranih spotova, 30 slogana se završava sa imenom i prezimenom kandidata, od kojih samo 3 sa imenom kandidatkinje, koje su suštinski bile bez ikakvih izgleda na izborima.

Predsednička kandidatkinja desničarske SRS, Jadranka Šeselj, žena osnivača ultra desničarske partije SRS kojem je u toku suđenje u Haškom tribunalu. U medijima je prepoznata kao „neodgovarajuća zamena”, a o njoj su pisali u štampi kao o „Šešelj ženi”. Ime joj je bilo vidljivo jedino u sloganu promotivnog TV spota.

\section{Primer: 1 SRS 2012.}

Verna Srbiji Jadranka Šešelj za predsednika

I kada su kandidatkinje eksplicitno navedene imenom i prezimenom u slogan 2012. nije korišćen rodno senzibilisan jezik. Dosledno je upotrebljen muški rod za imenicu ,kandidat” za ženu. Valja podsetiti da rodno osetljiv jezik nije u srpskom normiran (Savić et al. 2009). To je jedna od poruka da stranka koju reprezentuju (u ovom slučaju desno nacionalistički orijentisana SRS) zagovara tradicionalističke patrijarhalne vrednosti. 
Za razliku od Primera 1 u kampanji 2014. jedini spot koji je posvećen ženi i u kojem je i u sloganu prepoznata žena i to rodno senzitivnim jezikom je spot URSA koji je predložio kandidatkinju za ovu poziciju. Stranka ima demokratski program okrenut ekonomskom razvoju zemlje.

Primer: 2 URS 2014.

Grafičko rešenje zatvaranja spota: Suzana Grubješić za gradonačelnicu

Prezenter zatvara spot rečima: Suzana Grubješić Ujedinjeni regioni Srbije Da radimo i da živimo

\section{Telo spota}

Telo spota čini forma i sadržaj. U obe kampanje 2012. i 2014. po formi spotovi su bili hibridnog tipa čine ih: dokumentarni snimci sa terena, govor lidera u kame$\mathrm{ru}$, animicija, kratke igrane forme.

„Izbori su odmeravanje snaga, kao obaranje ruku, nešto plemenski, ljudi hoće da osete tu snagu. Važni su simbolički detalji u spotu, kao plemenski vođa, bik, čak i seksualna moć. Žena u takvoj konstelaciji ne može da se probije. Stranačke vođe odlučuju da su kampanje muške" (TL IDEA+).

Prema sadržaju spota možemo identifikovati nekoliko tipova: a) uspesi u prethodnom mandatu; b) kritika neostvarenih obećanja; c) obećanja za budućnost i d) prepoznavanje značaja rodne ravnopravnosti. U sve četiri kategorije dominiraju muški akteri.

Prepoznavanje značaja rodne ravnopravnosti sadržano je samo u jednom spotu i to 2012.

\section{Primer 32013.}

Ivica Dačić, Lider SPS:

„Svaka žena danas u Srbiji ima 8,5 odsto manju platu od mušakaraca. [...] ja ću ukinuti tu diskriminaciju. Žene i muškarci moraju da imaju istu platu na istom radnom mestu, sa istom školskom spremom."

U 2014. ni jedan spot nije imao sadržaj koji bi u bilo kojoj formi govorio o ženama ili rodnosti u ekonomiji, kulturi, politici, bilo kojoj sferi života.

Kampanja za sve nivoe izbora u Srbiji 2012. i 2014. je u potpunosti bila maskulinizirana sa pozicije moći partijskih lidera i na ikoničkom nivou i na nivou aktera koji su direktno govorili u kameru.

Uočeno je nekoliko diskursnih ikoničkih strategija: a) sami lideri stranaka u krupnom prvom planu, izgovaraju svoja predizborna obećanja direktno u kameru. Ovakvih je bilo najviše u 2014. b) Lideri stranaka na završnim konvencijama, ili mitinzima podrške, koji dominiraju scenom u euforičnom spektaklu, a sledbenici u masi kliču daleko dole ispod bine, nisu dovoljno rodno prepoznatljivi jer je 
snimak iz ptičije perspektive. Ovom strategijom su se služile velike populističke partije poput SPS i 012. i 2014. c) Lider stranke razgovara sa pojedincima u porodici, na poljoprivrednom imanju, u fabrici, na ulici. Anonimni pretežno muškarci i pokoja, najčešće mlada urbana devojka, (u dva samo slučaja žena sa bebom u naručju), daju otvorenu podršku lideru. Ovaj tip je identifikovan 2012. ali ne i 2014. d) Lider okružen timom zadubljen u rešavanje problema. U timu gotovo u potpunosti muškarci. Karakteristično za SNS 2012. Izostao 2014.

Društvena moć se očituje i u pravu na javni govor i zagovaranje sopstvenih ideja u javnoj sferi. U 40\% analiziranih spotova 2012. muškarci lideri direktno se obraćaju biračima. Više od lidera zabeležen je narator u $88 \%$ spotova, i samo u jednom naratorka. U kampanji 2014. Isklučivo u kameru govore lideri stranaka i nosioci lista, kao i naratori, samo u jednom spotu je zabeležena naratorka.

U spotovima 2012. su lidere stranaka neposredno, i njihove partije posredno, podržavale javne ličnosti među kojima je bilo 34 muškarca potpisana sa punim imenom i prezimenom, i duplo manje (15) poznatih žena. Podršku liderima je dalo još i 12 nepoznatih i nepotpisanih žena, kao i svega 2 nepoznata, ali potpisana muškarca. Ovaj tip spota je izostao 2014.

Žene su se pojavile samo u tri spota kao političarke koje zagovaraju svoje kandidature.

\section{Primer 4 DSS 2013.}

Sandra Rašković Ivić:

„Dragi prijatelji okrenimo se sebi. Na Đurđevdan glasajmo za budućnost, za sigurnost, za mir, za rad, za trud. Glasajmo da se naša deca školuju, rade i žive u svojoj zemlji [...]"

Žene u predizbornom TV spotu govore:

a) direktno o vrlinama ličnosti lidera kao porodičnog čoveka „Zato što je odgovoran otac četvoro dece, pa će biti odgovoran i za moju”; „Zaista mu verujem”;

b) o stranci koja brine o svakom pojedincu „Sa SNS svi ćemo imati jednake šanse";

c) o svom ličnom angažmanu kao vidu podrške stranci „Ja sam potpisala Vojvođanski preokret za slobodnu Vojvodinu";

d) o svojim potrebama koje očekuje da će joj rešiti kandidat/stranka „od 2008. ne može čovek sebi da kupi stan valjda je normalno da onaj koji radi može sebi da priušti krov nad glavom";

e) umesto lidera stranke govore negativno (poluistine) o oponentima „Nikolić i Vučić ${ }^{8}$ su se odrekli Kosova i Metohije."

Nisu na primer izlagale o unutrašnjoj politici, ekonomiji, rodnoj ravnopravnosti, iako su to važne teme u javnom životu Srbije. Ovi nalazi se podudaraju i sa našim prethodnim istraživanjima iz ove oblasti (Valić Nedeljković 2007, 2008)

\footnotetext{
Lideri nekad SRS, a sad SNS nacionalne stranke. Oni se i u okviru nove partije zalažu za Kosovo unutar
} Srbije. U spotu govori građanka koja podržava SRS. 
kao i sa onima iz drugih kultura, na primer Kira Sanbonmatsu/ Kathleen Dolan navode da ,političarke doživljavaju kao osobe koje poseduju pre svega tipično ženske osobine, na primer toplinu i saosećajnost, kao i da su eksperti u takozvanim ženskim pitanjima, kao što je obrazovanje" $(2009,485)$.

U kampanji 2014. pojavljue se samo jedna žena koja govori i to je spot URS za gradonačelnicu Beograda:

\section{Primer 5 URS 2014.}

Suzana Grubješič: Nećemo stezanje kaiša. A da beograđani ne ostanu kratkih rukava, ja sam spremna da zasučem svoje. Da normalno bude stalno.

U ovoj izjavi kandidtkinja za gradonačelnicu Beograda jasno koristi ženski princip „da zasučem svoje (odnosi se na „rukave”)”. Žene su uvek spremne da rade i umesto drugih i za dobro drugih i ova rečenica to odražava.

Kandidatkinja se spontano šeta ulicama Beograda, ulazi u gradski autobus (jedna je od nas), na igralištu pomiluje po glavi devojčicu duge kovrdžave plave kose (sterotip anđela, a kandidatkinja prototip brižne majke), vidimo je u radnom (ima karijeru) i partijskom (aktivistkinja) prostoru. Spot pokazuje i dokumentarni material o susretima sa poznatim ličnostima što ukazuje da kandidatkinja nije anonimus, to je važna implicitna poruka s obzirom da do izbora 2014. nije bila poznata širem auditorijumu kao javna ličnost.

Narator spot zaključuje rečima: radi za viziju, a ne za proviziju, i stopu po stopu dovodi Evropu. Suzana Grubješić da radimo i da živimo.

Završni tekst naratora šalje dve jasne poruke prva je da će se kandidatkinja boriti protiv korupcije, a druga da će dovesti nove investiture u Srbiju što jeste bila platform URS-a, partije koja ju je kandidaovala, u kampanji 2014.

Ovo je jedinstven primer afirmativnog promotivnog plaćenog predizbornog oglasa u kojem je kandidatkinja dobila priliku da, kao što je uobičajeno kada su partijski lideri u pitanju, bude prikazana u različitim ulogama, mada ipak na stereotipiziran način.

\section{Životne priče kandidatkinja (Oral history)}

U trećem feminističkom talasu u Srbiji (od 1990. na ovamo) izdiferencirale su se dve grupe žena: jedna aktivistička kojima je bio bliži radikalni feminizam (egzistencijalna ugroženost muškim nasiljem posebno u vreme ratnog raspada Jugoslavije) i druga liberalna koja se afirmisala političkim delovanjem osnivajući alternativni Ženski parlament i Žensku vladu9 , ali i boreći se za povećanje broja političarki u parlamentima Srbije, Vojvodine i lokalnih samouprava (Milić 2011, 59).

$\mathrm{U}$ ovom poglavlju u fokusu su pripadnice druge grupe.

U iznošenju ličnih iskustava o predizbornoj kampanji političarke su, bez obzira na partijsku pripadnost, koristile u svojim životnim pričama, iste diskursne stra-

Funkcionišu na nivou građanske inicijative, na žalost bez značajnog uticaja na dnevnu političku praksu. 
tegije. Negirale su postojanje bilo kakve unutarstranačke diskriminacije, seksizma, stereotipa i predrasuda, podržavale su lidera stanke. Insistirale su na:

a) neophodnosti timskog rada političarki bez obzira na stranačku pripadnost

„Što se tiče veće zastupljenosti žena na vodećim funkcijama u samim strankama, tu su ženske organizacije izuzetno bitne, zbog podržavanja jedna druge, a ne bi bilo loše da i kod nas, u Srbiji konačno zaživi saradnja ženskih organizacija različitih stranaka“"(EK/SVM).

b) Tvrdile su da partijski dokumenti prepoznaju rodnu ravnopravnost, ali da se ona ne sprovodi dosledno

„U skladu sa statutom predviđen je Forum žena Saveza vojvođanskih Mađara. Na žalost, problemi se najčešće javljaju u krugu samih žena, jer većina njih misli da je njihov zadatak da se bave humanitarnim radom, i retko učestvuju u donošenju odluka.“ (EK/SVM)

c) Rešenje vide u neophodnosti podrške muškaraca u obezbeđivanju rodne ravnopravnosti u stranci

„Izborni štab u kojem preovlađuju muškarci odlučuje ko će govoriti u medijima u kampanji, oni su neosetljivi na primedbe." (GČ/DS)

d) Sopstvenu nevidljivosti u medijskoj prezentaciji stranke opravdavaju opštim interesom.

„Medijsko vreme u plaćenoj televizijskoj kampanji je skupo i naša procena je bila da moramo da uradimo nešto provokativno što će biti zapamćeno. Odluka je bila da imamo tri lica kampanje, pre svega i najviše lider stranke i dva gradonačelnika samo lokalno (muškarac i žena) ${ }^{10}$." (MS/LSV, izbori 2012.)

Sve intervjuisane političarke su se složile da se u Srbiji još dugo ne može očekivati da žena bude predsednica velike stranke, odnosno kandidatkinja za predsednika države, ali da je proces u tom pravcu nezaustavljiv. „Naše sve stranke su liderske, ali ipak mislim kada bi sadašnji lideri ostvarili ciljeve koje su planirali, možda bi onda bili u stanju da prepuste to mesto i ženi” (SL/SNS).

\section{ZAKLJUČAK}

U sferi prinude (na primer rodno senzibilisano zakonodavstvo, kvote) uočen je značajan pomak u prisutnosti žena u parlamentu (32\% 2012. i 34\% 2014). U oblasti unutarpartijske politike $u$ odnosu na rodnu senzibilnost urađeno je jako malo. Identifikovano je i dalje odsustvo žena u predizbornom TV spotu i najčešće izostajanje rodno senzitivnog jezika u kampanji.

Ikonička i sadržajna prezentacija Srbije u izbornom ciklusu 2012., kao i 2014. kada je TV spot u pitanju, bila je ,jednorodna”, tačnije maskulizirana sa stanovišta moći u društvu koju poseduju partijski lideri muškarci. Nema ozbiljnije mizoginije nego što je strategija isključenosti iz političkog prostora posredovanog medijima. Dakle reč je o medijskoj, pa tako i šire društvenoj, nevidljivosti žena u ispoljavanju

$\overline{10}$ Na izbornoj listi za parlament Srbije ova stranka je imala 250 kandidata i kandidatkinja. 
osnovnog prava, a to je pravo na participiranju u donošenju odluka i aktivnom učestvovanju u izborima. Valja naglasiti takođe da je kampanja 2014. u potpunosti isključila ženu iz plaćenog političkog oglašavanja kao akterku, a na nivou „kulise” i „mizanscena” pojavljuje se sasvim sporadično.

Istovremeno u iznošenju ličnog iskustva u predizbornim kampanjama političarke su svesne da postoji raskorak između proklamovanog (rodna ravnopravnost, kvote, zastupljenost u parlamentu) i realnog (nevidljivost u medijskoj kampanji). Istovremeno smatraju da je implementacija rodne ravnoprvnosti u izborni ciklus nezaustavljiv proces.

Rezultati analize diskursa komparativno 2012. i 2014. su potvrdili osnovnu hipotezu da bez obzira što su, shodno zakonskim odredbama, na kandidatskim listama u oba analizirana izborna ciklusa, žene kandidatkinje zauzimale svako treće mesto - one su podzastupljene u plaćenom političkom medijskom reklamiranju (tv spotu). Potvrđene su takođe i pojedinačne hipoteze s tim da je prva ,žene u predizbornim tv spotovima zastupaju lik i delo lidera partije i nosioca liste" potvrđena u analiziranim tv spotovima samo u predizbornoj kampanji 2012. Druga je potpuno potvrđena u oba anlizoirana predizborna ciklusa (u vizuelnoj prezentaciji sadržaja spota kandidatkinje su podzastupljene). Treća, da rodno senzitivan jezik nije prisutan u sloganu i telu spota, je potvrđena u oba korpusa sa samo jednim izuzetkom u 2014. Četvrta da kandidatkinje nisu imale priliku da zastupaju svoje stavove i mišljenje u direktnim citatima u predizbornim tv spotovima, je potvrđena sa jednim izuzetkom, reč je o TV spotu za izbor gradonačelnice Beograda 2014.

Ovo istraživanje bi moglo poslužiti za dalja razmatranja životnih iskustva političarki u Srbiji, kao važnog činioca u kampanjama, ali i plaćenog medijskog oglašavanja, sa interkulturnog stanovišta, kao i iz dijahronijske perspektive, kako bi se ukazalo političkim partijama, i njihovim kreativnim timovima, na značaj rodno senzitivnog pristupa u modeliranju predizborne kampanje i otvorilo mogućnost za implementaciju modela bolje prakse.

\author{
NEVIDLJIVOST POLITIČARKI U PLAĆENOM OGLAŠAVANJU \\ predizborni tv spot, Srbija 2012 i 2014
}

\title{
REZIME
}

Rad se bavi kritičkom analizom diskursa (CDA) predizbornih TV spotova u poslednje dve kampanje 2012. i 2014. u Srbiji. Cilj istraživanja je da se iz rodne perspektive dekonstruišu strategije partija u oblasti rodne senzibilisanosti i to u najvažnijoj aktivnosti parlamentarne demokratije - izbornom ciklusu na primeru političkog plaćenog oglašavanja - predizbornog TV spota, na koji su stranke izdvojile najviše sredstava u kampanji 2012. i 2014. u Srbiji. Cilj je takođe da se analizira lično iskustvo političarki da bi se na nov i drugačiji način analizirale prakse i strategije partija u odnosu na vidljivost kandidatkinja u vreme predizborne kampanje medijima. 
Osnovna metoda je kritička analiza diskursa (CDA) nadopunjena komparativnom metodom poređenja kampanja redovnih izbora 2012. i vanrednih izbora 2014, kao i metodom životnih priča kandidatkinja (oral history). U CDA poseban naglasak se stavlja na različite oblike diskriminacije koji nastaju kao rezultati zloupotrebe moći koji dalje vode ka pojavi društvenih nejednakosti i nepravde (Dijk 2008).

Postoje tri nivoa na kojima se uočava (ne)vidljivost žena u političkim procesima: a) u predizbornim kampanjama (ne)prisustvo žena na kandidackim listama, a nakon izbora i u parlamentu; b) (ne)vidljivost žena u plaćenoj medijskoj kampanji i c) (ne)vidljivost žena u jeziku.

Praksa: a) Na osnovu ,principa afirmativne akcije” žene postaju prisutnije na kandidatskim listama i u parlamentu uvođenjem kvota kao rezultat rodno senzibilisanog zakonodavstva (sve zemlje SEE - Jugoistočna Evropa/Zapadni Balkan). b) Žene su i dalje retko vidljive u predizbornom tv spotu kao najučinkovitijem plaćenom oglašavanju, jer je to tradicionalno muški ,,prostor”, dok su žene aktivnije na terenu. c) Vidljivost žena u jeziku postiže se, na primer, primenom kodeksa rodno senzitivnog jezika (S. Savić 2004).

U ovom radu fokus je na tačkama (a) i (b), s tim da se (c) razmatra ograničeno, samo u okviru analize slogana predizbornog tv spota.

TV spot čine: slogan i telo spota. Slogan čini ikonički i jezički deo. U obe kampanje slogani, osim jednog (URS za gradonačelnicu Beograda) 2014, nisu bili rodno senzibilisani. Telo spota čini forma i sadržaj. U obe kampanje 2012. i 2014. po formi spotovi su bili hibridnog tipa čine ih: dokumentarni snimci sa terena, govor lidera u kameru, animicija, kratke igrane forme.

Analizom je potvrđena osnovan hipoteza: bez obzira što su, shodno zakonskim odredbama, na kandidatskim listama u oba analizirana izborna ciklusa, žene kandidatkinje zauzimale svako treće mesto - one su podzastupljene u plaćenom političkom medijskom reklamiranju (tv spotu).

Potvrđene su i pojedinačne hipoteze.

Ikonička i sadržajna prezentacija Srbije u izbornom ciklusu 2012, kao i 2014. kada je predizborni tv spot u pitanju, bila je maskulizirana sa stanovišta moći u društvu koju poseduju partijski lideri muškarci. Osnovna strategija svih partija koje su imale plaćenu televizijsku kampanju, u formi tv spota, u oba posmatrana predizborna ciklusa bila je strategija isključenosti iz poltičkog prostora posredovanog medijima. Dakle reč je o medijskoj, pa tako i šire društvenoj, nevidljivosti žena u ispoljavanju osnovnog prava, a to je pravo na participiranju u donošenju odluka i aktivnom učestvovanju u izborima.

Dubravka Valić Nedeljković

\section{INVISIBILITY OF FEMALE POLITICIANS IN PAID ADVERTISING pre-election TV clip, Serbia in 2012 and 2014}

\section{SUMMARY}

This paper deals with a critical discourse analysis (CDA) of pre-election TV commercials in the last two campaigns of 2012 and of 2014 in Serbia. The aim of the research is to deconstruct the strategy of political parties in the field of gender sensitization from a gender perspective based on the most important activity of parliamentary democracy - the election cycle, using examples of paid political advertising - the pre-election TV clip, for which the parties allocated the most resources in the campaign of 2012 and of 2014 in Serbia. The aim is also to analyze the personal experience of female politicians in order to provide a new and different way of analyzing practices and strategies of the parties in relation to the visibility of female candidate in the media during the election campaign.

The basic method is the critical discourse analysis (CDA) complemented by the method of comparing the regular election campaign of 2012 and the early elections of 2014, and the method of life stories of the candidates (oral history). The CDA puts a special emphasis on various forms 
of discrimination that result from the abuse of power that continues to lead to the emergence of social inequality and injustice (Dijk 2008).

There are three levels at which the (in)visibility of women in the political process can be observed: a) the (lack of) presence of women on the candidate lists in the election campaign, and after the elections, the (decreased) number of women in the parliament; b) (in)visibility of women in paid media campaigns and c) (in)visibility of women in the language.

Practice: a) On the basis of the "principle of affirmative action", women become more present on the candidate lists and in the parliament as a result of the introduction of quota into the gender sensitive legislation (all SEE countries - Southeast Europe/Western Balkans). b) Women are still rarely seen in the pre-election TV clip which is the most effective paid advertising, because it is a traditionally male "space", while women are more active in reach-out field work. c) visibility of women in language is achieved, for example, by the use of the Gender-sensitive language Code. (S. Savić).

In this paper the focus is on the sub-paragraphs (a) and (b), with (c) being analyzed in a limited manner only as part of the pre-election TV clip slogans analysis.

A TV clip is comprised of: the slogan and the body of the clip. The slogan is made of an iconic and a linguistic part. In both campaign slogans there were no gender sensitive slogans, except for one in 2014 (URS's campaign for the female Mayor of Belgrade). The body is made of the video format and the content. In both campaigns, in 2012 and in 2014 forms of videos were hybrid types that included: documentary footage from the field, speech of the leader speaking directly in camera, animation, short fiction form.

The analysis confirmed the basic hypothesis: despite the fact that, according to the legal provisions a female candidate occupied every third position of the candidate lists in both analyzed election cycles - they are underrepresented in paid political advertising in the media (TV clip). Individual hypotheses are also confirmed.

The icons and the contents of the presentation of Serbia in the election cycle in 2012 and in 2014 in the election TV clips were masculinized from the standpoint of power in society that is held by male party leaders. The basic strategy of all parties who had a paid television campaign, in a form of TV clips, in both observed election cycles was the strategy of exclusion from the political space mediated by the media. So we are here talking about a media, and by that, a wider social invisibility of women in exercising one of the fundamental rights, the right to participation in decision-making and active participation in the elections.

\section{LITERATURA}

Cantrell, T. H., \& Bachmann, I. (2008). Who is the lady in the window? A comparison of international and national press coverage of first female government heads. Journalism Studies, Vol. 9, No 3, 429-446.

Carolin, D.B., \& Winfrey, K. L., (2009). Have You Come a Long Way, Baby? Hillary Clinton, Sarah Palin, and Sexism in 2008 Campaign Coverage. Communication Studies, Vol. 60, No. 4, September-October 2009, 326-343.

Convention on the Elimination of All Forms of Discrimination Against Women (CEDAW Convention) (1979) http://www.un.org/womenwatch/daw/cedaw/text/econvention.htm

Dijk, T. A., (2008). Discourse and Power. Houndmills, Basingstoke, Hampshire: Palgrave Macmillan.

Ibroscheva, E., \& Raicheva-Stover, M. (2009). Engendering Transition: Portrayals of Female Politicians in the Bulgarian Press. The Howard Journal of Communications 20, 111-128.

Kaid, L. L., \& Holtz-Bacha, C. (2000). Gender Reactions to TV Political Broadcasts A Multicountry Comparison. Press/Politics 5(2), 17-29. 
Kendall, S., \& Tannen, D. (2010). Discourse and Gender. In: Schiffrin, D., \& Tannen, D., \& Hamilton, E. H. (Ed.) (2010). The Handbook of Discourse Analysis (pp. 548-567). USA/ UK/ Australia.

King, James D., \& McConnell, J. B. (2003). The Effect of Negative Campaign Advertising on Vote Choice: The Mediating Influence of Gender. Social Science Quarterly, Volume 84, Number 4, 843-857.

Kroon, Å., \& Ekström, M. (2007). Vulnerable woman, raging bull or mannish maniac? Gender differences in the visualization of political scandals. In: The Visual Communication Division at ICA'S (International Communication Association) Annual Conference in San Fransisco May 24-28, 2007. 1-26.

Matić, J. (2002). Mediji i izbori. Beograd : Centar za slobodne izbore i demokratiju.

Matić, J. (2007). Televizija protiv birača. Beograd : Dobar naslov.

Milić, A. (2011). Feministički talasi, orijentacije i pokreti u jugoslovenskom i srpskom duštvu 20. veka. U: Milojević, I. \& Markov, S. (urednice) (2011). Uvod u rodne teorije (51-64). Novi Sad: Mediterran Publiching.

Milivojević, S., \& Matić, J. (1993). Ekranizacija izbora. Beograd : Vreme knjige.

Montague, K., \& Paige P. E. (1994). Women candidates going public: the 30-second format. Argumentation \& Advocacy; Fall 94, Vol. 31 Issue 2, 80-96.

Moranjak-Bamburić, N., Jusić, T., \& Isanović, A. (2006). Stereotyping: Representation of Women in Print Media in South East Europe. Media discourse as a male domain: Gender representation in the daily newspapers of Bosnia and Herzegovina, Croatia and Serbia. Budapest : SEENPM.

The United Nations Millennium Development Goals (2000). http://www.unmillenniumproject. org/goals/gti.htm\#goal3

http://www.un-documents.net/mdg.htm

Pokrajinska skupštinska odluka o izboru poslanika u skupštinu Autonomne Pokrajine Vojvodine (2012). Službeni list AP Vojvodine, br. 3/2012

Republička radiodifuzna agencija/RRA (2012). Izbori 2012. http://www.rra.org.rs/uploads/ useruploads/PDF/1956-izvestaj_o nadzoru emitera_Izbori_2012..pdf

Republička radiodifuzna agencija/RRA (2014). Izbori 2014. http://www.rra.org.rs/uploads/ useruploads/izvestaji-o-nadzoru/IZBORI-2014---zavr_ni-izve taj.pdf

Salmon, K. (2011). Strategija Šeherezade. Beograd : CLIO.

Sanbonmatsu, K., \& Dolan, K. (2009). Do Gender Stereotypes Transcend Party?

Political Research Quarterly, Vol. 62, No. 3, 485-494.

Savić, S. (2004). Zena sakrivena jezikom medija: kodeks neseksističe upotrebe jezika u medijima. Novi Sad : Futura publikacije.

Savić, S. (2012). Recenzija. U: Subotički, D. (priredila) (2012). Životne priče političarki iz Vojvodine (124-125). Kikinda: Banatski kulturni centar.

Slavujević, Đ. Z. (2007). Izborne kampanje: Pohod na birače, Slučaj Srbije od 1990. do 2007. godine. Beograd : Institut društvenih nauka.

Valić Nedeljković, D. (2008). (Ne)vidljivost žena u političkom TV spotu? Analiza diskursa političkog tv spota u predizbornoj kampanji 2008 u Srbiji. U: Valić Nedeljković, D. (2008). Kandidatkinje (147-163). Novi Sad : Novosadska novinarska škola.

Zakon o javnom informisanju (2003). Službeni glasnik Republike Srbije br. 43/2003, 61/2005 i 71/2009. 
Zakon o izborun narodnih poslanika (2003). Službeni glasnik RS, br. 35/2000, 57/2003 odluka USRS, 72/2003 - dr. zakon, 75/2003 - ispr. dr. zakona, 18/2004, 101/2005 - dr. zakon, 85/2005 - dr. zakon, 28/2011 - odluka US, 36/2011 i 104/2009 - dr. Zakon

Zakon o lokalnim izborima (2007). Službeni glasnik RS, br. 129/2007, 34/2010 - odluka US i $54 / 2011$

Zeldes, G. A., \& Fico, F. (2005). Race and Gender: An Analysis of Sources and Reporters in the Networks' Coverage of the 2000 Presidential Campaign. Mass Communication \& Society, 8(4), 373-385. 